\title{
E SE MIA COUTO NÃO FOSSE AFRICANO? ${ }^{1}$
}

Otavio Henrique Meloni

(Instituto Federal de Educação, Ciência e Tecnologia do Rio de Janeiro - Campus Volta Redonda)

Quando falamos do moçambicano Mia Couto é difícil não nos remetermos ao seu universo narrativo tão vasto de obras e qualidades. Tendo iniciado sua carreira literária com a publicação do livro de poemas Raiz de Orvalho, em 1981, Mia desenvolveu uma obra narrativa bastante sólida e respeitada, não só em termos de produção estética, como também no que concerne à maneira como aborda temáticas sociais e políticas dos diferentes momentos do século XX em Moçambique. Cabe, ainda, ressaltar que é dessa sutil percepção que a obra de Mia Couto emerge, quase sempre amparada por personagens e situações que extrapolam o real para, assim, afirmar o próprio real.

Os livros de contos Cada homem é uma raça (1990), Estórias Abenssonhadas (1994) e Fio das missangas (2003), tornam evidentes as relações sociais e de força que se estabelecem em um Moçambique cindido entre as fortes marcas do período colonial, a nova proposta de administração local e os diversos sujeitos que, por motivos vários, estiveram à parte em todo o processo político e fizeram outras leituras do conturbado século $\mathrm{XX}$. Essa matéria também é comum a alguns de seus romances, notoriamente em Terra Sonâmbula (1992) e Um rio chamado tempo, uma casa chamada terra (2002), nos quais personagens movem histórias paralelas aos desdobramentos da condição colonial e de sua História, o que acaba por revelar, muitas vezes, que as fraturas tão preponderantes para alguns são indiferentes para outros por um simples motivo: há mundos diferentes que se movem em um mesmo espaço moçambicano. 
A habilidade em narrar esses mundos e suas fricções vem do olhar de um biólogo que por muito tempo trabalhou junto à ONU e à UNESCO em projetos dedicados à preservação ambiental, o mapeamento de áreas rurais do país e das culturas e povos ainda remanescentes em alguns desses territórios. Pode-se até questionar a relevância dessa prática e convívio como motriz para a criação de muitos de seus personagens e histórias; porém, o que podemos afirmar sem nenhuma dúvida é que as percepções sociais de um Moçambique recortado por tradições, culturas e modos de vida diferentes são fruto do aprendizado deste trabalho, aliado ao pensamento de alguém que se põe a refletir sobre os desdobramentos extranacionais e suas relações internas. Mia Couto, portanto, se torna um grande indagador de suas realidades - do escritor, do biólogo, do jornalista - em contato com as outras realidades de um mesmo Moçambique.

Assim, encontramos a reunião de ensaios e palestras intitulada $E$ se Obama fosse africano?, publicada no ano de 2011 pela Companhia das Letras no Brasil. Nesse volume, o escritor moçambicano reúne dezesseis textos que escreveu para apresentação em eventos, palestras e publicações acadêmicas. O título, homônimo a um dos ensaios, é instigante e provocador, principalmente se pensarmos sobre o estardalhaço feito por grande parte da mídia internacional após a eleição de Barack Obama para presidente dos Estados Unidos da América. O primeiro presidente negro da então maior potência econômica e bélica do mundo ocidental foi assunto das principais publicações ao redor do mundo e gerou bastante controvérsia sobre os conceitos de raça, racismo (aqui pensamos pelo viés do preconceito mesmo) e embaraços culturais. Talvez este não devesse ser o título do livro. Nunca sabemos se a escolha, em espaço tão comercial quanto o mercado livreiro, é feita pelo autor ou pelo editor. O que importa para nós é perceber que qualquer estratégia de marketing, neste caso, não ludibria o leitor fiel do escritor moçambicano, muito menos ilude os novos possíveis leitores do escritor, já que os dezesseis ensaios reunidos no volume dão conta de capturar, em palavras e longos espaços para reflexão, o espírito da obra literária de Mia Couto.

Se a proximidade do literário e do acadêmico pode assustar o desavisado que entenda por ensaio, estritamente, uma reunião de ideias concatenadas com argumentação sólida e desenvolvimento de técnicas dissertativas, não confunde o leitor cativo de Mia, na medida em que retrata bem a proposta estética de diluição dos gêneros e tipos textuais. Assim, as "conversas" do moçambicano sobre acontecimentos muito peculiares de Moçambique escapam para outras searas e acabam por delinear um contexto de reflexão no qual podemos ler e compreender Moçambique como uma experiência particular, mas marcadamente plural.

Logo no texto que abre o volume, de título "Línguas que não sabemos que sabíamos”, Mia Couto apresenta uma visão interessante sobre o conceito de língua, ressaltando que não nos apercebemos de que nossa prática de vida, cada vez mais pragmática em meio aos "certos e errados" 
de uma sociedade padronizada por modelos, anula por completo o potencial criador de algumas das situações mais simples e cotidianas que poderíamos desenvolver. Neste sentido, falar e escrever se tornou uma prática tão "banal" que refletir sobre o significado e o peso daquilo que dizemos e pensamos é quase um luxo. Assim, quando nos deparamos com a abordagem do moçambicano, seu texto leva o leitor a inserir-se no texto, de modo a fazê-lo dialogar com sua própria realidade. Não se trata apenas, no referido ensaio, de pensar as dificuldades inerentes à tarefa de traduzir contextos culturais distintos para línguas construídas de acordo com realidades também diversas. Trata-se, em última instância, de perceber que não somos capazes, com palavras, de expressar e compreender a realidade do outro. A complexidade do conceito de língua está em sua relação com cada um de seus falantes, as línguas que inventamos e as próprias modificações que fazemos a fim de adaptá-la à nossa realidade.

Mia Couto sabe que a língua, seja a portuguesa ou qualquer outra, será sempre incapaz de aprisionar sentidos, muito menos traduzi-los por completo. Seu trabalho incansável em adequar línguas e linguagens para que sejam capazes de contar suas histórias, muitas vezes as histórias dos outros, demonstra o quanto esse tema interfere na elaboração estética de seu universo narrativo. A escrita literária do moçambicano, sempre dialogante com os aspectos da realidade peculiar de personagens-metáforas tradutores de muitas outras percepções da mesma realidade, se transpõe para o primeiro dos ensaios, discutindo a importância dessa percepção para o entendimento da complexidade cultural e linguística de Moçambique. Cabe ressaltar que esta discussão não se restringe a uma questão meramente antropológica, Mia está preocupado em construir uma reflexão sobre a forma como ignoramos a importância da comunicação - não importa por que linguagem - e como isso, de certa forma, anula diferenças e fortalece uma padronização comportamental que contribui, consequentemente, para o apagamento das outras realidades de cada espaço. Assim, o próprio Mia Couto assinala que "as línguas servem para comunicar. Mas elas não apenas "servem". Elas transcendem essa dimensão funcional. Às vezes, as línguas fazem-nos ser” (COUTO, 2011, p. 13-14).

Somos por aquilo que dizemos, pensamos e escrevemos em qualquer linguagem ou língua. A mensagem de abertura é esta e assim nos encaminhamos para os outros ensaios, passeando por temas sempre próximos da realidade africana, mas não distantes da realidade do mundo como um todo. A fome e a miséria são personagens das narrativas ensaísticas de um escritor que sempre se apresentou como um questionador de seu espaço. A África, o continente, será sempre o ponto de partida ou de chegada de uma reflexão mais ampla sobre aspectos humanísticos e sociais. Mia Couto levará seu leitor, ao longo dessa compilação de artigos, ao estado ambíguo de apreciação da linguagem - muitas vezes literária - e a reflexão contínua sobre as mazelas do continente africano mesmo após a libertação dos antigos sistemas coloniais. Assim, encontraremos sua voz indagando 
"presidentes" que estão no poder por décadas a fio, sem qualquer tipo de estrutura democrática. Encontraremos a relutância em aderir a alguns discursos fáceis que impõem ao continente como um todo o estigma de atraso. O autor de "Cada homem é uma raça" é contundente quando diz que

A atitude de nos fabricarmos a nós mesmos como simples vítimas é uma das principais razões para os problemas de África e dos africanos. Todo o nosso discurso continua centrado na culpabilização do passado colonial e da dominação estrangeira. A culpa é sempre o Outro. Esse outro pode ser uma outra raça, uma outra etnia, uma outra religião. Nós estamos sempre isentos de procurar dentro de nós as causas profundas dos nossos problemas. (COUTO, p. 139-140)

O estereotipo de vítima, posto em xeque pelo autor, dialoga com a necessidade de repensar todo o continente africano dentro de outra lógica de comunidade internacional. Nesse sentido, não há uma negação do passado histórico marcado por tantas tragédias e exploração por parte dos impérios e posteriores nações ricas, principalmente da Europa. Trata-se, isto sim, da constatação de que não é possível modificar os caminhos das novas nações africanas sem antes revistar seu próprio espaço, sua própria realidade e questionar qual a parcela de culpa de cada um diante da estagnação financeira e social e do apagamento cultural que muitas etnias e povos estão sofrendo por todo o continente. Mia Couto se dirige aos seus, se assim podemos chamar, a fim de alertar, outra vez em escalas maiores, para o fato de que a desumanização das decisões mais simples do cotidiano está empobrecendo a sociedade, seja ela qual for. Os rótulos e estigmas se tornaram, neste cenário, válvulas de escape para justificar práticas mesquinhas que beneficiam poucos em detrimento de muitos.

Assim chegamos ao artigo que dá nome ao livro de ensaios e norteia, de certa forma, as discussões apresentadas em cada um deles. No artigo, a instigante pergunta não quer permanecer sem resposta, mas tudo o que a cerca parece nos recobrar o fato que o presidente dos Estados Unidos não é africano. E aqui é que os temas debatidos e apresentados ao longo do livro começam a se enlaçar. A alternância entre a euforia pela vitória de Obama e a desilusão pela impossibilidade de uma vitória como essa em África surge das reflexões do escritor sobre questões preponderantes para compreender seu continente. Obama não pode ser africano pois em África não é negro, sua mestiçagem indica a marca do outro, não poderia afirmar e agradecer o apoio das minorias, dentre tantas coisas. As marcas que impediriam Barak Obama de ser eleito em qualquer país africano, na verdade, são as que - na visão do moçambicano - impedem as nações africanas de crescer e garantir os direitos básicos a todos os seus cidadãos. A crítica de Mia Couto recai, então, sobre o sistema, os vícios e sobre o apego ao poder que determinados "líderes" africanos possuem e exercem em seus espaços.

E se Obama fosse africano? vale a leitura tanto pelo aspecto literário da escrita de Mia Couto - mesmo se tratando de ensaios -, quanto pela 
ousadia crítica que tais textos revelam. Ler o continente africano pelas palavras de Mia pode provocar alguma angústia no leitor desavisado, aqueles que não são tão familiarizados com as análises que o autor costuma fazer, velada ou abertamente, em seus contos, romances e poemas. A experiência africana de Mia Couto transcende qualquer complexo de vítima, qualquer falsa manutenção do tradicional para fortalecer interesses econômicos e políticos de pequenos grupos. No ensaio que nomeia o livro, o autor aponta um dos obstáculos para a impossível eleição de Obama em África: “Sejamos claros: Obama é negro nos Estados Unidos. Em África ele é mulato. Se Obama fosse africano veria sua raça atirada contra o seu próprio rosto." (COUTO, 2011, p. 200) Assim, ficamos com as palavras do moçambicano para questioná-lo: "E se Mia Couto não fosse africano?". Não parece necessário listar atributos e vantagens para responder tal pergunta; basta dizer que se isso fosse verdade, os ensaios deste livro teriam pouca valia. Obrigado Mia Couto, obrigado!

\section{REFERÊNCIA BIBLIOGRÁFICA}

COUTO, Mia. E se Obama fosse africano? e outras intervenções. São Paulo: Companhia das Letras, 2011.

\section{NOTAS}

1 Resenha do livro de ensaios E se Obama fosse africano? 